\title{
PEMBERDAYAAN MASYARAKAT SEBAGAI STRATEGI RESOLUSI KONFLIK SOSIAL
}

\author{
M. Dharmariza, Rahmad Hidayat, dan Miftah Faridl Widhagdha \\ PT Pertamina (Persero) RU II Sungai Pakning
}

\begin{abstract}
In the context of Pertamina Refinery Unit II Production River Pakning as one of the oil and gas processing companies operating in the Bukit Batu region, Bengkalis, Riau with the characteristics of rural communities, the management of social conflicts is crucial because it is not only to maintain the reliability of oil and gas processing operations but also corporate sustainability in terms of social, economic and environmental aspects. Community empowerment carried out within the framework of environmental social responsibility (TJSL) or better known as Corporate Social Responsibility (CSR) is one of the strategies in the resolution and mitigation of social conflict. The existence of a community empowerment program carried out by the company to communities around the operational area is carried out in a participatory manner starting from planning, implementation to monitoring and evaluation so as to be able to involve the active role of stakeholders, especially the community. As a result, during the implementation of the community empowerment program from 2017 to 2018 , it was not only able to improve the quality of people's welfare but also the tendency of a decrease in the number of cases and social conflicts with the community. In addition, the implementation of participatory community empowerment programs is also able to be a mitigative effort to manage relations with the community and stakeholders before ending into social conflict. The impact is that in a sustainable manner, the social relations between the company and the community are well established, the economic welfare of the target communities has increased, and the quality of the environment has improved thanks to a community empowerment program.
\end{abstract}

\begin{abstract}
Abstrak: Pengelolaan konflik dalam tata kelola pemangku kepentingan (stakeholders) merupakan salah satu instrument penting yang menjamin keberlanjutan organisasi. Dalam konteks Pertamina Refinery Unit II Production Sungai Pakning sebagai salah satu perusahaan pengolahan minyak dan gas yang beroperasi di wilayah Bukit Batu, Bengkalis, Riau dengan karakteristik masyarakat pedesaan, pengelolaan konflik sosial menjadi krusial karena tidak hanya untuk menjaga kehandalan operasional pengolahan minyak dan gas namun juga keberlanjutan perusahaan baik dari sisi sosial, ekonomi dan lingkungan. Pemberdayaan masyarakat yang dilakukan dalam kerangka tanggung jawab sosial lingkungan (TJSL) atau yang lebih dikenal dengan Corporate Social Responsibility (CSR) merupakan salah satu strategi dalam resolusi dan mitigasi konflik sosial. Keberadaan program pemberdayaan masyarakat yang dilakukan oleh perusahaan kepada masyarakat yang berada di sekitar wilayah operasional dijalankan secara partisipatif mulai dari perencanaan, pelaksanaan hingga pengawasan dan evaluasi sehingga mampu melibatkan peran aktif pemangku kepentingan, terutama masyarakat. Hasilnya, selama pelaksanaan program pemberdayaan masyarakat dari tahun 2017 sampai dengan 2018, tidak hanya mampu meningkatkan kualitas kesejahteraan masyarakat namun juga kecenderungan menurunnya jumlah kasus dan konflik sosial dengan masyarakat. Selain itu, pelaksanaan program pemberdayaan masyarakat yang partisipatif juga mampu menjadi upaya mitigatif untuk mengelola hubungan dengan masyarakat dan pemangku kepentingan sebelum berakhir menjadi konflik sosial. Dampaknya secara keberlanjutan, hubungan sosial antara perusahaan dan masyarakat terbina dengan baik, kesejahteraan ekonomi masyarakat binaan meningkat, serta kualitas lingkungan hidup meningkat berkat adanya program pemberdayaan masyarakat.
\end{abstract}

Kata kunci: pemberdayaan masyarakat, strategi resolusi, konflik sosial, CSR

\section{PENDAHULUAN}

Kebakaran hutan dan lahan dalam beberapa tahun ini menjadi salah satu bencana nasional yang ada di Indonesia. Khusus pada lahan gambut, proses pemadaman berlangsung sulit karena api yang menyebar melalui bawah tanah pada lapisan gambut. Salah satu kawasan gambut yang sering mengalami kebakaran lahan dan hutan berada di Provinsi Riau. Berdasarkan data dari Kementerian Lingkungan Hidup dan Kehutanan, Provinsi Riau memiliki luas hutan dan lahan terbakar yang cukup luas, pada tahun 2015 saja, kebakaran hutan dan lahan di Provinsi Riau mencapai 183.808 ha (Sumber: http://sipongi. menlhk.go.id) Kebakaran hutan yang terjadi umumnya diakibatkan dua hal, secara sengaja 
dan tidak sengaja. Kebakaran secara sengaja kebanyakan dipicu oleh pembakaran untuk membuka lahan dan pembakaran karena eksploitasi sumber daya alam. Sedangkan kebakaran tak disengaja lebih disebabkan oleh cuaca yang panas, pembakaran sampah, membuang puntung rokok, dan tindakan kelalaian lainnya. Menurut Wahana Lingkungan Hidup Indonesia atau Walhi, kebakaran hutan dan lahan di Riau merupakan salah satu bencana tahunan yang disebabkan oleh perilaku manusia. Fakta lapangan menunjukkan bahwa ada faktor kesengajaan membakar hutan dan lahan. Tujuan pembakaran tersebut adalah untuk melakukan pembersihan lahan dalam rangka persiapan pembangunan perkebunan.

Penangananan kebakaran hutan dan lahan di Riau tidak hanya menjadi fokus Pemerintah Provinsi Riau saja, namun juga menjadi perhatian pihak swasta yang berada di wilayah tersebut, salah satu pihak swasta nasional yang terlibat dalam penanganan kebakaran hutan dan lahan di Riau adalah PT Pertamina (Persero) Refinery Unit (RU) II Sungai Pakning. Sebagai salah satu perusahaan yang berada di wilayah Provinsi Riau, Pertamina ikut andil dalam upaya penanganan bencana kebakaran lahan dan hutan melalui program Corporate Social Responsibility (CSR) dengan melaksanakan Program Mitigasi Kebakaran Lahan dan Hutan Berbasis Pemberdayaan Masyarakat terutama pada lokasi Ring 1 perusahaan. Program ini dilaksanakan di 4 desa dan 1 kelurahan yang termasuk dalam Kecamatan Bukit Batu, Kabupaten Bengkalis. Keempat desa itu adalah Desa Sejangat, Desa Pakning Asal, Desa Sungai Selari, dan Desa Batang Duku, serta satu kelurahan yaitu Kelurahan Sungai Pakning. Upaya mitigasi ini dilakukan dengan memberdayakan Masyarakat Peduli Api (MPA), sebuah kelompok sukarelawan yang dibentuk khusus untuk merespon, mencegah dan memadamkan kebakaran hutan dan lahan di tingkat desa (Fauzan, Purwanto, Widhagdha, \& Pakpahan, 2017).

Pemberdayaan Masyarakat Peduli Api (MPA) didasarkan pada lemahnya ikatan sosial dan kelembagaan yang ada di antara MPA sehingga upaya penanganan kebakaran hutan dan lahan tidak dapat dilakukan secara optimal. Terbatasnya sumber daya manusia dan peralatan pemadaman di masing-masing desa menjadi kendala tersendiri dalam upaya mitigasi kebakaran hutan dan lahan. Untuk itu, penelitian ini akan mengungkapkan upaya Pertamina untuk meningkatkan ikatan sosial dan kelembagaan antar MPA agar penanggulanan bencana kebakaran hutan dan lahan dapat dilakukan secara optimal

\section{METODE}

Penelitian ini dilakukan menggunakan metode kualitatif yang merupakan prosedur penelitian untuk menghasilkan data deskriptif dari obyek penelitian yang diamati. Metode ini melihat pengalaman individu/organisasi secara utuh, sehingga tidak membatasi pernyataan individu/ organisasi ke dalam hipotesis tertentu. Sementara pendekatan yang dilakukan adalah studi kasus dengan melihat secara kasuistik mengenai pelaksanaan Program Mitigasi Kebakaran Hutan dan Lahan di Provinsi Riau olehCSR PT Pertamina (Persero) Refinery Unit II Sungai Pakning selama kurun waktu tahun 2018. Pengumpulan data dilakukan melalui observasi partisipan dan Focus Group Discussion (FGD). Informan penelitian dipilih berdasarkan purposive sampling dengan maksud agar informan yang dipilih sudah mengetahui permasalahan secara mendalam sehingga dapat memberikan informasi yang utuh. Informan penelitian adalah ketua dan para tokoh dalam kelompok Masyarakat Peduli Api (MPA), Forum Komunikasi Masyarakat Peduli Api (FORKOMPA) Bukit Batu dan Koperasi Tani Tunas Makmur yang ada di wilayah Sungai Pakning.

\section{HASIL DAN PEMBAHASAN Mitigasi Kebakaran Hutan dan Lahan melalui Restorasi Lahan Gambut}

Dalam pelaksanaan Program CSR Mitigasi Kebakaran Hutan dan Lahan berbasis Pemberdayaan Masyarakat yang dilakukan oleh PT. Pertamina (Persero) RU II Sungai Pakning, perusahaan mengajak dan memberdayakan masyarakat untuk memanfaatkan kembali lahan bekas kebakaran menjadi lahan produktif dan 
restoratif dengan melakukan beberapa hal, yaitu pertama, Pertamina mengajak masyarakat untuk menanam pohon khas gambut pada lahan-lahan bekas terbakar. Penanaman lahan bekas terbakar yang ada di Sungai Pakning dilakukan bersama Koperasi Tani Tunas Makmur dan Kelompok Masyarakat Peduli Api (MPA) Kelurahan Sungai Pakning. Penanaman pada lahan bekas terbakar ini bertujuan mengubah semak yang rawan terbakar menjadi lahan pertanian yang produktif dan menurunkan tingkat risiko kebakaran lahan. Saat ini, upaya penghijauan kembali lahan bekas terbakar telah mencapai lahan seluas 14,5 ha, yang terdiri dari tanaman nanas serta tanaman keras seperti durian(Durio Zibethinus), matoa (Pometia Pinnata), jengkol (Archidendron Pauciflorum) dan sirsak (Annona Muricata). Dipilihnya jenis-jenis tanaman tersebut karena selain bernilai ekonomis juga tidak perlu dilakukan pengolahan lahan lanjutan seperti pembakaran lahan gambut untuk penanaman.

Selain itu, upaya kedua yang bertujuan sebagai kegiatan restoratif adalah dengan mengembangkan Arboretum Gambut. Upaya pengembangan Arboretum Gambut dilakukan dengan kerja sama Masyarakat Peduli Api (MPA) Sungai Pakning dan Koperasi Tani Tunas Makmur ini berada pada lahan asli yang terselamatkan dari kebakaran dengan luas lahan 1,1 Ha. Di Arboretum Gambut ini kelompok bersama PT Pertamina RU II Sungai Pakning mengidentifikasi tanaman khas gambut yang terselamatkan dari kebakaran lahan dan hutan, serta berupaya membudidayakan tanaman khas gambut sehingga tidak terancam dari kepunahan. Beberapa tanaman langka yang konservasi dalam kegiatan ini antara lain Kantong Semar(nepenthes spectabilis), Meranti (Shorea Pinanga), Jelutung (Dyera Castula Hook), Palem Merah (Crytoctachys Lakka). Tanaman-tanaman ini termasuk dalam kategori endemik yang hanya dapat tumbuh dengan baik di lahan gambut.

Selain memiliki fungsi restorasi, Arboretum gambut juga memiliki fungsi edukasi dengan menjadi sarana pembelajaran bagi siswa sekolah maupun peneliti dari universitas yang ada di sekitar wilayah Sungai Pakning sebagai labo- ratorium pembelajaran lapangan. Secara ekonomi Arboretum Gambut juga memberikan pemasukan tersendiri bagi kelompok pengelola dari hasil penjualan tiket, makanan, maupun tanaman-tanaman hasil budidaya yang bisa dibawa pulang oleh pengunjung.

\section{Modal Sosial dalam Penanggulangan Bencana Asap}

Penanganan kebakaran hutan dan lahan selain dilakukan melalui kegiatan restoratif juga dilakukan dengan memanfaatkan modal sosial yang ada di masyarakat. Hal ini dikarenakan bentuk dan sifat kelompok Masyarakat Peduli Api (MPA) yang cenderung didasari pada sikapsikap kesukarelawanan (Hidayat \& Widhagdha, 2017), juga karena terbatasnya sumber daya yang ada di masing-masing desa untuk menanggulangi kebakaran hutan dan lahan di wilayah mereka. Secara sederhana modal sosial merupakan kemampuan masyarakat untuk melakukan koordinasi dan kerja sama antara sekelompok individu dalam memperjuangkan tujuan-tujuan mereka. Menurut Putnam (1993) dalam buku Rahmat Rais (2009) Terdapat beberapa elemen penting dalam modal sosial, seperti pranata sosial (social institutions), kepercayaan (trust), dan jaringan sosial (network) yang saling berkaitan.

Ketiga elemen modal sosial ini berperan penting dalam aktifitas yang dilakukan oleh MPA. Pranata sosial merupakan nilai dan norma yang dijadikan kepercayaan bersama oleh masyarakat, kepercayaan ini akan menentukan terbentuknya jaringan-jaringan sosial antar masyarakat guna memudahkan tercapainya tujuan kelompok (Widhagdha, 2018). Elemen-elemen modal sosial tersebut antara lain:

\section{Pranata Sosial (Social Institution)}

Pranata sosial sendiri terbagi atas norma dan sanksi yang merupakan komponen penting modal sosial dan harus diperhatikan jika ingin melihat apakah suatu hubungan bisa tercipta dengan baik atau tidak dalam suatu komunitas atau kelompok masyarakat. Dalam kelompok MPA, setiap desa telah memiliki peraturan guna memenuhi norma, namun perlu disadari pemahaman norma bersama belum cukup menjamin kerjasama antar individu karena selalu saja ada 
yang tidak taat terhadap norma yang telah disepakati (moral hazard). Oleh karena itu dibutuhkan sanksi sosial yang bersifat informal sehingga kualitas hubungan dan interaksi sosial tetap terjaga dengan baik. Penerapan dari sanksi sosial dalam pranata sosial adalah pada tahun 2018 ketika kelompok MPA dari salah satu desa yakni Desa Batang Duku tidak atau jarang aktif dan berpartisipasi, baik dalam rapat kelompok, kegiatan rutin maupun pemadaman api maka sesuai peraturan yang telah ditetapkan, anggotaanggota kelompok MPA Desa Batang Duku tersebut dikeluarkan dan diganti dengan yang baru yang lebih berkomitmen.

\section{Kepercayaan (Trust)}

Kepercayaan merupakan hal terpenting dalam sebuah hubungan, salah satunya hubungan pada suatu kelompok atau komunitas. Tanpa adanya rasa saling percaya di antara anggota komunitas, maka kerjasama tidak akan tercipta secara baik. Bentuk kepercayaan yang ada pada anggota MPA ini terlihat dari cara mereka saling berinteraksi satu sama lain. Sikap saling percaya antar anggota juga muncul karena MPA didasari pada bentuk-bentuk kesukarelawanan sosial, sehingga masing-masing anggota saling percaya untuk dapat menjalankan tugas dan fungsi masingmasing.

Untuk menjaga sikap saling percaya ini, anggota kelompok menerapkan 3 sikap dasar seperti kejujuran, kedekatan dan keterandalan. Kejujuran dalam bergaul, dimana keterbukaan dan transparansi telah menjadi prinsipnya, mendekatkan diri satu sama lain agar lebih mengerti pribadi dan permasalahan yang dihadapi masingmasing anggota kelompok, sehingga terjalin kedekatan dan keakraban serta mereka saling mengandalkan satu sama lain, dimana terdapat suatu pembuktian apakah mereka dapat memenuhi harapan diri sendiri, anggota kelompok dan masyarkat sekitar dengan terlaksananya kegiatan pencegahan dan pemadaman kebakaran hutan dan lahan.

\section{Jaringan Sosial (Social Network)}

Jaringan sosial merupakan salah satu faktor yang tak kalah pentingnya untuk dapat menunjang keberlangsungan hidup bersama. Pada kelompok MPA sendiri hal yang ditempuh untuk dapat menciptakan jaringan sosial adalah dengan menjalin hubungan yang baik, dengan sesama anggota MPA satu desa, dengan anggota MPA lain desa dan juga dengan masyarakat sekitar. Mereka saling bekerja dan berkoordinasi satu sama lain baik dalam pekerjaan mereka sebagai sukarelawan pemadam api maupun dalam kehidupan sehari hari. Melalui adanya jaringan sosial ini, efektivitas pemadaman api yang dilakukan sangatlah optimal, terbukti dengan berkurangnya titik api di Kecamatan Bukit Batu pada tahun 2015 dari sebanyak 2972 menjadi 156 titik api (sumber: www.bpbdkabbengkalis. go.id).

Keberadaan jaringan sosial yang menghubungkan MPA antar desa juga mendorong terbentuknya Forum Komunikasi MPA(FORKOMPA) se-Bukit Batu. Forum ini merupakan wadah bersama MPAdi Kecamatan Bukit Batu untuk saling berinteraksi, bertukar informasi dan saling membantu sumber daya manusia maupun peralatan ketika desa lain membutuhkan bantuan.

Terbentuknya FORKOMPA ini selain didasari keberadaan ketiga elemen modal sosial yang telah dijelaskan sebelumnya juga karena adanya kebutuhan bantuan sumber daya antar desa sehingga masing-masing anggota desa dalam FORKOMPA saling membutuhkan. Hal ini merupakan bentuk dari Resiprositas (Reciprocity) atau hubungan timbal balik. Resiprositas pada kelompok MPAdinilai cukup baik dimana ketika kebakaran hutan/lahan terjadi disalah satu tempat maka secara otomatis kelompok MPA dari desa manapun turut serta dalam melakukan pemadaman tidak hanya dari kelompok MPA yang desanya terkena kebakaran saja. Resiprositas memungkinkan anggota MPA antar desa saling membantu satu sama lain, memberikan timbal balik dengan menolong desa lain yang terkena kebakaran. Penerapan resiprositas ini adalah pada bulan Maret 2019 ketika Desa Sungai Selari mengalami kebakaran lahan maka tidak hanya MPA desa tersebut saja yang bergerak, mereka mendapat bantuan dari MPA Desa Batang Duku dan Kelurahan Sungai Pakning, begitu juga sebaliknya. Hal ini merupakan bentuk gotong-royong yang sudah menjadi prinsip kerja mereka. 


\section{Relasi dalam Modal Sosial sebagai Faktor Penguat Kelembagaan Sosial}

Keempat elemen modal sosial yang telah dijelaskan di atas menjadi dasar penting sebagai penghubung MPAdengan tanggung jawab yang ada sebagai sukarelawanan pemadam kebakaran. Modal sosial telah menjembatani mereka untuk semakin dekat dan menimbulkan bentuk-bentuk relasi modal sosial yaitu bonding, bridging serta linking pada hubungan mereka baik dalam pekerjaan maupun kekerabatan (Widhagdha, n.d.).

Bentuk relasi bonding, bridging dan linking ini lebih terasa ketika kelima kelompok MPAini disatukan atas inisiatif dari PT Pertamina RU II Sungai Pakning sebagai pembina CSR dari MPA. Kelompok MPA ini disatukan dan diberi nama Forum Komunikasi MPA(FORKOMPA), guna memudahkan komunikasi antar anggota kelompok dari berbagai desa. Keberadaan FORKOMPA dirasa tidak hanya menguatkan relasi bonding di dalam masing-masing MPA, namun juga memperkuat relasi bridging antar MPA desa (Widhagdha, 2019). Dengan adanya lembaga FORKOMPA, anggota MPA memiliki kekuatan yang lebih untuk berinteraksi dengan lembaga-lembaga lain di luar mereka, termasuk berinteraksi dengan pemerintah desa, TNI/ POLRI dan Pertamina.

Setelah terbentuk FORKOMPA, kegiatan pemberdayaan masyarakat yang dilakukan Pertamina melalui program CSR pun menjadi lebih terarah dan bermanfaat. Beberapa kegiatan yang dilakukan setelah terbentuknya FORKOMPA antara lain Pelatihan Safetyman dan Fireman, Pelatihan Kewirausahaan dan Latihan Gabungan antara FORKOMPA, TNI, POLRI, HSSE Pertamina untuk kesiapan penanggulangan kebakaran hutan dan lahan.

Selain itu dengan terbentuknyaFORKOMPA semakin memudahkan anggota untuk berkoordinasi satu sama lain tidak hanya saat pelatihan pemadaman dan kegiatan pemadaman saja namun juga dalam kegiatan rutin sehari-hari seperti pemberian penyuluhan-penyuluhan kepada masyarakat tentang pentingnya menjaga lingkungan untuk pencegahan kebakaran, patroli lapangan yang dilakukan setiap pagi dan sore, pembuatan sekat kanal, sumur bor, serta kolam penampungan air di titik-titik rawan terbakar. Melihat pada kasus terbentuknya FORKOMPA, keberadaan modal sosial sejatinya merupakan potensi yang ada pada masyarakat dan dapat digunakan sebagai pendorong perubahan ke arah yang lebih baik lagi untuk menyelesaikan berbagai masalah secara kolektif, mendorong roda perubahan di tengah masyarakat, memperluas kesadaran bersama bahwa banyak jalan yang bisa dilakukan oleh setiap anggota kelompok untuk memperbaiki nasib secara bersama-sama.

\section{Kontribusi dalam Pencapaian Tujuan Pembangunan Berkelanjutan (TPB)/ Sustainable Development Goals (SDGs)}

Program CSR yang dilakukan oleh PT Pertamina (Persero) RU II Sungai Pakning melalui Mitigasi Kebakaran Hutan dan Lahan berbasis Pemberdayaan Masyarakat yang membina Masyarakat Peduli Api (MPA) juga telah berkontribusi dalam pencapaian Tujuan Pembangunan Berkelanjutan (TPB) atau Sustainable Development Goals (SDGs). Setidaknya, program ini telah berperan aktif dalam upaya mencegah terjadinya dampak buruk akibat perubahan iklim (TPB 13) dan menjaga ekosistem daratan (TPB 15) dengan upaya restoratif pada lahan gambut. Upaya ini telah dilakukan melalui pengembangan Arboretum Gambut dan penanaman kembali lahan bekas terbakar dengan tanaman endemik khas gambut. Dari kedua aktivitas ini, telah mendorong pertumbuhan ekonomi (TPB 8) bagi masyarakat di sekitar wilayah pengembangan. Kegiatan ekonomi ini muncul melalui kegiatan pengelolaan arboretum, pertanian nanas, hingga pengolahan nanas menjadi aneka produk bernilai ekonomis sehingga mampu membuka lapangan kerja bagi masyarakat sekitar.

\section{SIMPULAN}

Keberadaa modal sosial yang ada pada Masyarakat Peduli Api (MPA) telah mendorong terciptanya kelembagaan sosial berupa Forum Komunikasi MasyarakatPeduliApi(FORKOMPA) yang terbentuk berdasarkan kesamaan pranata sosial (social institution), sikap saling percaya 
(trust), jaringan sosial (networks), dan hubungan timbal balik (reciprocity). Terbentuknya kelembagaan sosial juga didorong adanya relasi sosial yang telah ada di masyarakat seperti kuatnya bonding di dalam anggota MPA, terjalinnya bridging antar anggota MPA di masing-masing desa, dan menguatnya relasi linking antar MPA dengan pihak-pihak lain. Adanya kelembagaan sosial ini turut mendukung terlaksananya program Mitigasi Kebakaran Hutan dan Lahan berbasis Pemberdayaan Masyarakat melalui kegiatan restoratif yaitu pengembangan Arboretum Gambut dan kegiatan produktif yaitu penanaman kembali lahan terbakar dengan tanamantanaman endemik lahan gambut.

\section{DAFTAR RUJUKAN}

Fauzan, F., Purwanto, W., Widhagdha, M. F., \& Pakpahan, D. P. (2017). Pemetaan Kawasan Rawan Karlahut Berbasis Sistem Informasi Geografi dan
Partisipasi Masyarakat di BukitBatu. dalam Prosiding Seminar Nasional Geografi: Peran Geografi dalam Pengelolaan Sumberdaya Wilayah NKRI di Era Teknologi (pp. 895-905).

Hidayat, R., \& Widhagdha, M. F. (2017). Peran Modal Sosial dalam Pemberdayaan Masyarakat (Studi Kasus Pembinaan UMKM oleh PT Pertamina RU II Sungai Pakning).

Widhagdha, M. F. (n.d.). Role of Capital Social Bonding, Bridging and Linking in Community Empowerment (Case Study of CSR Partner PT Pertamina RU II Sungai Pakning).

Widhagdha, M. F. (2018). Role of Social Capital in Community Empowerment (Case Study of CSR Partner PT Pertamina RU II Sungai Pakning).

Widhagdha, M. F. (2019). Relasi Sosial dalam Praktik CSR. Surakarta: Arjuna Wijaya. 